\title{
ПОРЯДОК УЧЕТА ОПЕРАЦИЙ С ПОИСКОВЫМИ АКТИВАМИ
}

\begin{abstract}
Julia.IceQueen.07.01.94@mail.ru
С принятием нового Положения по бухгалтерскому учету (ПБУ) 24/2011 «Учет затрат на освоение природных ресурсов» в практическую деятельность бухгалтерского учета были приняты инновачионные дефиниции, что повлекло за собой потребность в дополнении учетной политики для предприятий - пользователей недр. В приведенной статье будут рассмотрены и охарактеризованы особенности бухгалтерского учета поисковых активов на основе актуальных нормативных документов. Рассмотрен отечественный и зарубежный опыт по ведению учета поисковых активов. Проанализированы мнения выдающихся спечиалистов в области бухгалтерского учета в отношении особенностей ведения учета по материальным поисковым активам и нематериальным поисковым активам, а также их способов отражения в бухгалтерском балансе. Предложены способы отражения амортизации вышеуказанных активов, а также их обесценения.
\end{abstract}

Ключевые слова: поисковые активы, поисковые затраты, амортизачия поисковых активов, себестоимость актива.

Добывающая отрасль, на сегодняшний день, является одной из самых востребованных отраслей в Российской Федерации. Данный вид отрасли вносит в себя ряд предприятий и организаций, занимающиеся постоянным поиском и разработкой природных месторождений. Поэтому деятельность таких предприятий нашла отражение в бухгалтерском учете. Отдельно взятые аспекты бухгалтерского учета таких организаций в данной отрасли, во многом зависит от особенностей технологической деятельности в процессе поиска, разведки, оценки и добычи полезных ископаемых. Но ведение бухгалтерского учета в приведенной отрасли, относительно организаций, ведущих разработку природных ископаемых, до 2012 года регламентировались только общепринятыми для всех отраслей актами, а особенности отражались только в подзаконных актах. Однако, в процессе совершенствования бухгалтерского учета в отношении международных стандартов, с 2012 года, был введен особый стандарт Положение по бухгалтерскому учету (ПБУ) 24/2011 об «Учете затрат на освоение природных ресурсов», что, очевидно, вызвало вопросы в новых понятиях, их формах, спецификациях учета, установленных в ПБУ.

Таким образом, необходимо сформировать единые методологические подходы к применению данного ПБУ, найти решения, связанные со спорными аспектами в операциях, связанных с ведением деятельности хозяйствующих субъектов относительно недр, в рамках Плана счетов. Перечисленные аспекты указывают на актуальность данной работы и устанавливают ее цель, как теоретическое обоснование ведения отчетности в рамках ПБУ24/01, на современных предприятиях, ведущих поиск, разработку и добычу природных ископаемых.

Вышеуказанный бухгалтерский акт применяется в организациях, осуществляющих комплекс действий по разработке, добыче и оценке природных ископаемых на отдельно взятой области недр. Для ведения данной деятельности, хозяйствующий субъект должен получить лицензию.

Основным предметом в бухгалтерском учете относительно ПБУ 24/2011, являются поисковые затраты. Под поисковыми затратами принято понимать расходы на геологоразведку, а именно: оценку, поиск, разведку полезных ископаемых. При ведении учетной политики предприятия, необходимо устанавливать способ или метод распределения поисковых затрат расцениваемых, как внеоборотные поисковые активы, и затратами на обычную деятельность [2].

Необходимость по разделению затрат была перенята из международных актов ведения учета в рамках деятельности по освоению природных недр, а именно из стандарта IFRS 6 «Разведка и оценка запасов минеральных ресурсов», a также FAS 19 «Учет и отчетность нефтегазодобывающих компаний».

Исходя из международного опыта, перераспределение поисковых затрат на капитализированные, образующие стоимостное выражение внеоборотного актива, а также расходов текущего периода формируется путем применения способов учета. Способы учета представляют собой перечень методов: метод успешных усилий, метод участков, приносящих прибыль, метод учета полных затрат и метод ассигнований.

Метод учета полных затрат представляет собой капитализацию совокупности издержек, 
затрачиваемых в процессе геологоразведки в независимости от результатов.

Метод успешных усилий представляет собой капитализацию, исключительно, успешной поисково-разведывательной деятельности, вернее издержек на благополучный результат функционирования данной деятельности.

Использование метода участков, приносящих доход, построено на точном распределении издержек относительно отдельно взятых участков, на которых проводили геологоразведочную деятельность. Исходя из этого, капитализация распространяется исключительно на издержки участков, которые обоснованы для разработки, и они имеют необходимые полезные ископаемые.

Метод ассигнований является тождественным с методом благополучных усилий, отличие состоит в том, что амортизация сформированного поискового актива не начисляется.

В процессе анализа ПБУ 24/2011 было установлено, что приведенный акт имеет схожий характер с методом благополучных усилий и методом ассигнований, но разница все же есть, и заключается в том, что хозяйствующим субъектам ведущих разработку на территории России, необходимо самим сформировать перечень поисковых затрат, которые формируют цену поисковых активов.

Как в Российском, так и в мировых стандартах, поисковые активы разделяются на материальные и нематериальные. Материальные активы, например, могут включать в себя буровые машины, насосные станции, системы доставки ископаемых из недр и т.д. К нематериальным активам можно отнести права на ведение геологодобывающей деятельности, заключения по разведке и проведению геологических исследований, акты, включающие результаты по бурению и исследованию найденных пород, а также коммерческие акты.

В бухгалтерии, предметом учета основных средств на основании ПБУ 6/01 и нематериальных активов соответствующим ПБУ 14/07 выступает инвентарная единица. Российские хозяйствующие субъекты, ведущие геологоразведочную деятельность, должны отражать в учете инвентарные единицы материальных и нематериальных поисковых активов, относительно актов в бухгалтерском учете, которые упомянуты выше [8].

Некоторые из специалистов, в частности М.Ю. Медведев, не разделяет мнения, что нематериальные поисковые активы необходимо обособить. Автор считает, что изменения в отношении бухгалтерского учета, принятые 29 июля 2013 года, установившие норму о признании затрат, понесенных предприятием в отчет- ном периоде, однако, данные затраты относятся к последующим отчетным периодам в составе активов, которые учитываются по функционирующим правилам бухгалтерского учета, апеллируют относительно экономических понятий сформированных трат, которые, в конечном итоге, могут оказаться экономически не целесообразными. Но в финансовом учете, установленным федеральными нормами, необходимо уделять внимание на действующие редакции нормативно-правовых актов, в которых указана вся правовая база для признания данных объектов учета [5].

В формирование оценки поисковых активов отечественного ПБУ 24/2011 и международного IFRS 6 была включена по себестоимости. Комплекс издержек, внесенных в себестоимость поискового актива, указан в таблице 1.

В основе комплекса издержек, по отношению Российских стандартов, лежит классификация по видам, а в основе издержек по международным актам, в основе лежит классификация по видам осуществляемых работ. Образование фактической себестоимости поискового актива в отношении ПБУ 24/11 основывается на общих подходах, которые используются в ПБУ 6/01, ПБУ 14/07 и т.Д., но различия состоят во включении в себестоимость обязательств по охране окружающей среды и рекультивации земельных участков. Данный акт соответствует пункту 11 IFRS 6.

В ПБУ 24/11 указаны только несколько норм в отношении поисковых активов, из этого акцентируем внимание на их анализе. Согласно пункту 9 ПБУ 24/2011 предусмотрено, что «материальные и нематериальные поисковые активы учитываются на отдельных субсчетах к счету учета вложений во внеоборотные активы». При этом хозяйствующим субъектам логично ввести в рабочий план счетов три субсчета к счету 08 «Вложения во внеоборотные активы»: - 08.9 «Осуществление поисковых затрат»;

- 08.10 «Материальные поисковые активы»;

- 08.11 «Нематериальные поисковые активы» [5].

Поисковые издержки формируются в следующем виде:

Дебет 08.9 - Кредит 10, 70, 69, 76 и т.д.

Включение в себестоимость поисковых активов оценочных обязательств происходит таким образом:

Дебет 08.9 - Кредит 96 «Резервы предстоящих расходов».

При заключении процесса формирования поискового актива, когда предприятие получило инвентарный объект, вносится запись: 
Дебет 08.10, 08.11 - Кредит 08.9 на величину фактических издержек, основанных на формировании актива.

Таблица 1

Затраты, вносимые в себестоимость поискового актива

\begin{tabular}{|c|c|}
\hline ПБУ 24/2011 & IFRS 6 \\
\hline $\begin{array}{l}\text { - Средства, отчисляемые по договору поставщи- } \\
\text { кам; } \\
\text { - Средства, отчисляемые предприятиям за оказание } \\
\text { услуг по договору строительного подряда, а так же } \\
\text { других договоров; } \\
\text { - Плата посредническим организациям, с помощью } \\
\text { которых покупается поисковые активы; } \\
\text { - Платежи, отчисляемые консалтинговым фирмам; } \\
\text { - Таможенные пошлины и сборы; } \\
\text { - Госпошлины и патентные пошлины; } \\
\text { - Амортизационные отчисления внеоборотных ак- } \\
\text { ти-вов, использованных при включении поискового } \\
\text { актива; } \\
\text { - Заработная плата рабочим, занятых формирова- } \\
\text { нием поискового актива; } \\
\text { - Затраты на отчисления в фонды охраны окружа- } \\
\text { ющей среды, ликвидации зданий, сооружений, обо- } \\
\text { рудования, выполняемые в ходе геологической де- } \\
\text { ятельности, рекультивации земельных участков, } \\
\text { разведки и оценки природных ископаемых, при } \\
\text { формировании и становлении поисковых активов; } \\
\text { - Другие затраты, имеющие отношение с покупкой, } \\
\text { созданием поисковых активов [4]. }\end{array}$ & $\begin{array}{l}\text { - Отчисления на покупку на проведение разведоч- } \\
\text { ных работ; } \\
\text { - Затраты на геологическую деятельность; } \\
\text { - Отчисления на поисковое бурение; } \\
\text { - Затраты на пробу и исследование образцов; } \\
\text { - Затраты, относящиеся на оценку экономической } \\
\text { целесообразности добычи природных ископае- } \\
\text { мых[6]. }\end{array}$ \\
\hline
\end{tabular}

Отдельно стоит акцентировать внимание на последующей оценке поисковых активов, так как этот аспект является весьма спорным. Исходя из пункта 12 IFRS 6 предприятие устанавливает модель учета по фактическим затратам или же по переоцененной стоимости. Так же устанавливается связь с IAS 16 и IAS 38. Исходя из актов отечественного учета, в то время, когда актив формируется, его оценка происходит по фактическим затратам, а именно с месяца, следующего за месяцем принятия к учету, по материальным поисковым активам происходит начисление амортизации по ПБУ 6/01, а в отношении нематериальных поисковых активов на основании ПБУ 14/2007.

В ПБУ существует четыре способа начисления амортизации, наиболее признанным является линейный метод, включающий срок полезного использования. Сроки полезного использования формируются из ПБУ 6/01 и 14/2007, но существует важный аспект: актив признается поисковым еще до принятия решения об экономической целесообразности всей геологоразведывательной деятельности. Предприятие имеет право устанавливать такой срок согласно сроку лицензии, на добычу природных ископаемых. Так же в ПБУ 24/2011 в пункте 18 делается акцент, что издержки на получение лицензии, которая дает право на разведку и оценку недр, а также добыче ископаемых, амортизации не подлежат.

Далее следует отдельно рассмотреть вопрос о начислении амортизации поисковых активов. Это можно обосновать тем, что вопрос о начислении амортизации относительно данного вида актива в финансовом учете еще не решен. Некоторые из специалистов в области учета, а именно Е.Ю. Диркова и И.В. Овчинникова считают, что начисленную амортизацию необходимо формировать на отдельных субсчетах к счетам 02 и 05 и отнести это к дебету счета 99. Но такой взгляд, со стороны указанных авторов, является не совсем верным. В процессе поиска, разработки земельных недр в целях получения полезных ископаемых может привести к двум результатам: успешному, когда ископаемые найдены и дальнейшее ведение деятельности является целесообразным, и когда, получен отрицательный результат, и, следовательно, процесс будет считаться экономически не выгодным, в то время, как предприятие для получения результата занимается созданием поисковых активов. Это может быть дорога к месту добычи, установка скважин и т.д. Поэтому, амортизация на объект, который используются в данный момент в целях формирования нового актива, считается частью фактических затрат и в учете имеет вид: 
Дебет 08.9 «Осуществление поисковых затрат» - Кредит 02 «Амортизация основных средств», 05 «Амортизация нематериальных активов».

Вышеуказанное суждение отражено актом в ПБУ 24/2011, пункт 17.

Стоит отметить, что планом счетов учета, применение счета 02 и 05 в целях начисления амортизации поисковых активов не предполагается. Следовательно, по моему мнению, необходимо обратить внимание на способ начисления амортизации в исключении применения счетов 02 и 05 , а использовать кредитование счетов 08.10 и 08.11. В данном случае, поисковые активы учитываются по остаточной стоимости.

В виду отсутствия нормативных актов, обеспечивающих порядок отражения амортизации поисковых активов в учете, организациям следует использовать вышеуказанное предложение в учетной политике.

В ПБУ 24/2011 пункт 19 указано, что предприятию необходимо производить анализ обесценивания поисковых активов на каждый отчетный период, что засвидетельствовано в указанном пункте четырьмя признаками. В случае наличия таких признаков, необходимо скорректировать балансовую стоимость, путем отражения обесценивая в порядке, указанном в IAS 36. Характерной чертой отличия IAS 36 от отечественного ПБУ 24/2011, является наличие не четырех, а десяти признаков обесценивания. Важным аспектом является не количество признаков обесценивания, а признание убытков вследствие обесценивания, в случае, если стоимость актива, которая возмещается, окажется меньше балансовой стоимости. В итоге, разница возмещаемой и балансовой стоимости будет убытком, который отражается в финансовом отчете [6].

В приведенной статье не указаны методики оценки возмещаемой стоимости поисковых активов, но было указано внимание на отражение обесценивания в учете по плану счетов. Исходя из ПБУ 10/99 суммы уценки активов являются прочими расходами предприятия и, следовательно, в учете прописываются по дебету счету 91.2 «Прочие расходы». Что касается корреспондирующего счета, то он не имеет единой системы, поэтому выделяют несколько подходов, о самом удачном подходе, на наш взгляд, мы поговорим ниже.

Данный подход был составлен в организации АКГ «Развитие бизнес-систем». Коллективом данной организации было предложено вносить обесценивание с применением дополнительного контрактного счета 06 «Обесценивание поисковых активов», по дебету 91.2 и кредиту
06. В Российской Федерации уже используется аналоги данного подхода. Так, использование оценочных резервов под уменьшение цены материальных ценностей, учитываемых на счете 14 , и под обесценивание материальных вложений, на счете 59.

Предприятия, ведущие деятельность в данной сфере могут сформировать свои подходы и внести их в учет, но на наш взгляд, разобранный подход является наиболее верным, так как его использование может помочь найти информацию о первичной и последующей стоимости объекта, суммы отчислений без корректировок и количества убытков от обесценивания данных активов. По ПБУ 24/2011 пункту 21 поисковый актив учитывается в учете, до того, как подтвердится экономическая целесообразность развития и добычи ископаемых, либо при признании экономической нецелесообразности. Следовательно, если экономическая целесообразность подтверждается, то предприятие начинает проверку поисковых активов на предмет обесценивания, затем отражает его и включает актив к основным средствам или нематериальных активов по остаточной стоимости [1]. В зависимости от того, кокой способ выбран по отражению амортизации и обесценения накопленные суммы будут списаны, а перевод активов получит вид, как: 08.10 .

Дебет 01 «Основные средства» - Кредит

Дебет 04 «Нематериальные активы» - Кредит 08.11 , а в случае признания экономической нецелесообразности, остаточная стоимость поискового актива подлежит списанию.

Таким образом, в данной статье были охарактеризованы теоретические аспекты ведения учета поисковых активов в отношении ПБУ $24 / 2011$, на основе отечественного и зарубежного опыта. Были указаны варианты отражения амортизации и обесценивания поисковых активов, который носят инновационный характер и имеют практическую значимость. Предложения по отражению амортизации поисковых активов может быть апробировано на предприятиях.

\section{БИБЛИОГРАФИЧЕСКИЙ СПИСОК}

1. Аглямова Л.Ф. Учет расходов на поиск, оценку и разведку полезных ископаемых // Экономика и менеджмент инновационных технологий. 2013. № 4 URL: http://ekonomika.snauka.ru/2013/04/2111 (11.01.2018).

2. Демакова О. А., Овчинникова И. В. Анализ применения положения по бухгалтерскому учету «Учет затрат на освоение природных ресурсов» (ПБУ 24/ 2011) на примере бухгалтерской отчетности ОАО «Распадская» // Проблемы 
и перспективы экономики и управления: материалы II Междунар. науч. конф. города СанктПетербург (июнь 2013 г.). СПб.: Реноме, 2013. C. 70-74.

3. Зылёва Н.В., Скрипин Д.Л. О возможностях анализа поисковых затрат на основе показателей внешней отчетности // Вестник Омского университета. Серия «Экономика». 2015. №1. С. 24-29.

4. Климов А. Новации бухгалтерской отчетности для добывающих компаний // Экономика и жизнь. 2012. №13 (9429). С. 11-13.

5. Медведев М.Ю. ПБУ 24/2011 «Учет затрат на основе природных ресурсов». Актуальный комментарий. М.: Изд-во ДКМ Пресс, 2012. 243 c.

6. Международный стандарт финансовой отчетности (IAS) 36 «Обесценение активов»: прил. 24 к приказу Министерства финансов РФ от 25 ноября 2011 г. №160н.

7. Международный финансовый стандарт отчетности (IFRS) 6 «Разведка и оценка запасов природных ископаемых»: прил. 35 к приказу Министерства финансов РФ от 25 ноября 2011 г. №160H.

8. Положение по бухгалтерскому учету «Учет нематериальных активов» (ПБУ 14/2007): приказ Министерства РФ от 27 декабря 2007 г. №153H.

9. Учет затрат на освоение природных ресурсов (ПБУ 24/2011): приказ министерства финансов РФ от 6 октября 2012 г. №125н.

10. Учет расходов на научноисследовательские, опытно-конструкторские и технологические работы (ПБУ 17/02): приказ Министерства финансов РФ от 19 ноября 2002 г. № $115 \mathrm{H}$.

\section{Информация об авторах}

Супрун Юлия Сергеевна, магистрант кафедры учета, анализа и аудита.

E-mail: Julia.IceQueen.07.01.94@mail.ru.

Белгородский государственный национальный исследовательский университет НИУ БелГУ.

Россия, 308015, Белгород, ул. Победы, д. 85.

\section{Поступила в январе 2018 г.}

(C) Сапрун Ю.С., 2018

\section{J.S. Suprun}

\section{THE PROCEDURE OF ACCOUNTING OPERATION WITH THE SEARCH ASSETS}

With adoption of accounting at 24/2011: "Expenditure accounting for developing of natural resources» in practical occupation of accountancy were accepted innovation definitions; was resulted in requirement in addition of account policy for the enterprises of consumer entrails. In this article particularities accountings of search assets on the basis of current reserve documents will be discerned and defined. Domestic and foreign experience are considered in accounting search assets. Opinions of eminent specialists are analyzed in the field of accounting in relation to the features of accounting for tangible assets and intangible assets, as well as their ways of reflecting in the balance sheet. The ways of reflection in the balance of depreciation for gory assets and their impairment.

Keywords: search assets, exploration costs, depreciation exploration assets, prime cost of assets.

\section{REFERENCES}

1. Aglyamova L.F. accounting of costs for the claim, evaluation and exploration of minerals. Economics and management of innovative technologies. 2013, no. 4 URL: http://ekonomika.snauka.ru/2013/04/2111 (11.01.2018).

2. Demakova O.A., Ovchinnikova I. V. Analysis of the application of the provision on accounting " accounting of costs for the development of natural resources "(PBU 24/ 2011) on the example of accounting of JSC" Raspadskaya". Problems and prospects of Economics and management: materials II interna-tional. scientific. Conf. cities of St. Petersburg (June 2013). SPb.: Renome, 2013, pp. 70-74.
3. Syliva N. In. Skipin D. L. On the analysis of search costs on the basis of external reporting indicators. Bulletin of Omsk University. Economy Series, 2015, no. 1, P. 24-29.

4. Klimov A. Innovations of accounting parity for mining companies. Economics and life. 2012, no.13 (9429), pp. 11-13

5. Medvedev M.Yu. PBU 24/2011 "Accounting of expenses on the basis of natural resources". Actual comment. M.: DCM Press publishing House, 2012. 243 p.

6. International financial reporting standard (IAS) 36 Impairment of assets: Annex. 24 to the order of the Ministry of Finance of the Russian Federation of November 25, 2011 №160N.

7. International financial reporting standard (IFRS) 6 "Exploration and evaluation of natural 
resources": Annex. $35 \mathrm{~K}$ at kazoo of the Ministry of Finance of 25 November 2011, no. 160n.

8. Regulation on accounting "Accounting for intangible assets" (PBU 14/2007): order of the Ministry of the Russian Federation, no. 153n of 27 December 2007.

9. Accounting of expenses for the development of natural resources (PBU 24/2011): order

Information about the author

Julia S. Suprun, Master student.

E-mail: Julia.IceQueen.07.01.94@mail.ru.

Belgorod National Research University.

Russia, 308015, Belgorod, Pobedu st., 85.

Received in January 2018 of the Ministry of Finance of the Russian Federation dated October 6, 2012, no. 125n.

10. Accounting of expenses for research, development and technological works (PBU 17/02): under the Ministry of Finance of the Russian Federation dated November 19, 2002, no. 115n. 